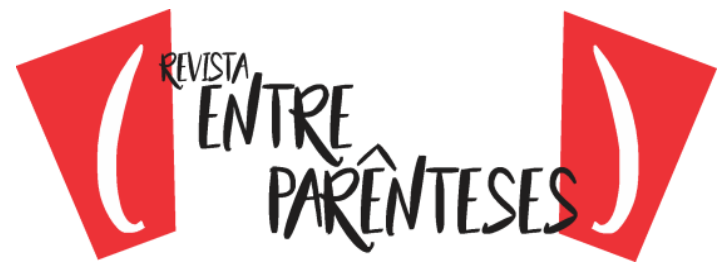

\section{OS DESDOBRAMENTOS COLONIAIS: PURPLE HIBISCUS COMO METÁFORA PARA A IDENTIDADE NIGERIANA}

\author{
Fidelainy Sousa Silva ${ }^{1}$ \\ Universidade Federal do Rio Grande do Sul \\ (fidelainys@gmail.com) \\ Lis Yana de Lima Martinez ${ }^{2}$ \\ Universidade Federal do Rio Grande do Sul \\ (yana.flafy@gmail.com)
}

\begin{abstract}
Resumo: Quando o lugar de silêncio é imposto ao subalterno, as tradições não só enfraquecem, mas há uma anulação total desse sujeito. A partir de obras literárias como Purple Hibiscus, acreditamos ser viável conhecer as implicações da influência colonialista, mesmo no período pós-colonial, quanto ao processo de aculturação dos sujeitos colonizados. Neste artigo, portanto, nos propomos a investigar os conflitos e os paradoxos culturais narrados pela protagonista de Adichie. Para tanto, nos faremos valer de aspectos integrantes do discurso da narradora, mas também, de observações pautadas nos postulados pós-coloniais a partir do enredo. Nosso objetivo é questionar as responsabilidades do texto literário nesse processo de (re)interpretar os discursos sobre as imagens dos nigerianos.
\end{abstract}

Palavras-chave: identidade; subalternidade; colonização; Purple Hibiscus.

Abstract: When the subaltern is imposed to occupy a place of silence, the traditions not only grow weak, but there is a total annihilation of the local people. From literary works such as Purple Hibiscus, we believe it is feasible to apprehend the implications of colonialist influence, even in the postcolonial period, on the process of acculturation of colonized subjects. Therefore, in this article, we propose to investigate the conflicts and the cultural paradoxes narrated by the protagonist of Adichie. To do so, we will make use of integral aspects of the narrator's discourse, but also of observations based on the postcolonial postulates from the plot. Our objective is to question the responsibilities of the literary text in this process of (re) interpreting discourses on Nigerian images.

Keywords: identity; subalternity; colonization; Purple Hibiscus.

Resumen: Cuando el lugar de silencio es impuesto al subalterno, las tradiciones no solo enflaquecen, como también hay una anulación del sujeto. A partir de obras literarias como Purple Hibiscus, creemos ser posible conocer las implicaciones de la influencia colonialista, aún en el periodo poscolonial, en lo que se refiere al proceso de aculturación de los sujetos colonizados. En este artículo, por lo tanto, nos proponemos investigar los conflictos y las paradojas culturales narrados por la protagonista de Adichie. Para esto, partiremos de los aspectos integrantes del discurso de la narradora, además de observaciones pautadas en los postulados poscoloniales a partir del enredo. Nuestro objetivo es cuestionar las responsabilidades del texto literario en ese proceso de reinterpretar los discursos sobre las imágenes de los nigerianos.

Palabras-clave: identidad; subalternidad, colonización, Purple Hibiscus.

\footnotetext{
${ }^{1}$ Doutoranda em Estudos de Literatura pelo Programa de Pós-Graduação do Instituto de Letras UFRGS.

2 Doutoranda em Estudos de Literatura pelo Programa de Pós-Graduação do Instituto de Letras UFRGS. Atua na área de Teoria, Crítica e Comparatismo tendo sua pesquisa voltada aos estudos Intermidiáticos, Intertextuais e Interdisciplinares.
}

Revista (Entre Parênteses) 


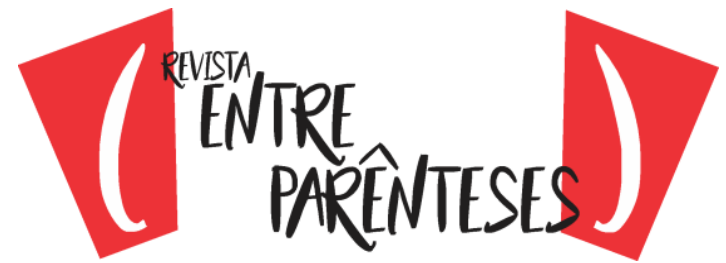

"...my point is that the only authentic identity for the African is the tribe...I am Nigerian because a white man created Nigeria and gave me that identity. I am black because the white man constructed black to be as different as possible from his white. But I was lgbo before the white man came."

(Chimamanda Ngozi Adichie)

\section{Introdução}

Em Purple Hibiscus, a escritora Chimamanda Adichie contextualiza suas personagens em uma narrativa que transparece a doutrina colonizadora, que com sua doutrina civilizatória abalizou conceitos hierárquicos sobre o que era bom, justo, necessário e correto na Nigéria. No texto, percebe-se que durante o período colonial as hierarquias de poder foram consideradas e ensinadas como uma seleção natural e determinista quando, em verdade, se tratava de criações provenientes de discursos de cunho político e econômico. Os ensinamentos coloniais passados causaram a marginalização de países colonizados, como a Nigéria, e as consequências desse processo resultou em culturas conflitivas e paradoxais como a que Adichie demonstra em seu romance. Purple Hibiscus é: uma obra permeada de questões históricas mal resolvidas sobre o imaginário unificado de religião e de nação subserviente aos interesses do colonizador. Se no século $X X$ a colonização não era mais territorial, no caso da obra que nos propomos analisar, isso não significa que ela era inexistente ou um mal já superado. Ela estava nos estereótipos e prejulgamentos culturais produzidos pelos colonizadores e que, como um espelho, refletem o passado colonizado e, mais que isso, determinariam um futuro de enfrentamentos discursivos.

Parte da revisitação histórica do século XX e dos imaginários coloniais, de certo modo, aconteceu com base nos questionamentos sobre a relação de superioridade de uma nação em relação a outra realizados por Edward Said na sua obra Orientalismo, que marca os primórdios dos estudos pós-coloniais. Nessa obra, as intenções do autor de questionar a história contada sobre o Oriente Médio estava 


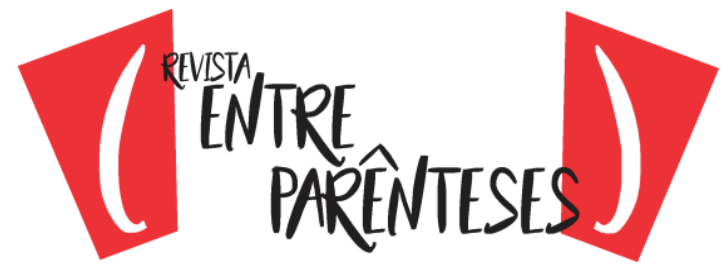

pautada no interesse maior do Ocidente de compreender o imaginário de homogeneização do Oriente. Said não aceitava que o Oriente fosse descrito como um único bloco cultural. O teórico demonstra também em outras obras a necessidade de se revisitar e se questionar todas as histórias e imaginários sobre os países que sofreram domínio territorial e ideológico. Países que tiveram a imagem inventada e divulgada como verdade. As pretensões de revisitação sobre o discurso homogeneizador que Said se propôs a realizar ao ir em busca das camadas de sentido do discurso ocidental sobre a cultura oriental é a mesma que seguimos para o eixo analítico deste trabalho. São os desdobramentos da homogeneização cultural nigeriana pós período colonial e os processos identitários provenientes desse período necessário para compreender as situações das personagens de Chimamanda Adichie.

Neste artigo, nos propomos a investigar os conflitos e paradoxos culturais narrados pela protagonista de Purpl eHibiscus. Nosso maior objetivo é demonstrar, a partir da obra escolhida, que, atualmente, há obras literárias que, assumem a postura investigativa de revisitar e questionar o quadro de imagem cultural e identitária única.

\section{2. $O$ perigo da história única}

$\mathrm{Na}$ conferência intitulada "The danger of a single story", a escritora nigeriana contemporânea Chimamanda Ngozi Adichie questiona quais os motivos para a unificação da história africana e a homogeneização da imagem cultural de um continente. Adichie considera que o enfraquecimento das práticas culturais dos países africanos acontecera dentro das instituições estatais. A religiosidade desses povos foi desmontada ao ponto de que os próprios africanos também acreditassem na ineficiência de suas tradições. A escritora contemporânea redimensiona o olhar para os perigos de uma única história contada sobre o continente africano.

Essa postura está na mesma esteira teórica de Edward Said: "A relação entre o Ocidente e o Oriente é uma relação de poder, de dominação, de graus variados de uma complexa hegemonia" (SAID, 2007 p. 31). Ou seja, é a Revista (Entre Parênteses) 


\section{("ifirer}

fragmentação intencional da África através dos aparelhos ideológicos do estado (igrejas, escolas, relações comerciais), inseridos pelos colonizadores, que enfraquece ou anula a identidade nacional. A contrapartida desse processo é que a África passa ser visualizada por outras nações por esse discurso "montado" por seus colonizadores. Como chamou Chimamanda "a história única" é dissimulada e destrói a história antes do processo colonial tornando-se um recorte perigoso e irreversível à medida que se infiltra na identidade das novas gerações. Como postulado por Ella Shohat e Robert Stam, "destituir os povos de sua cultura e transformar um povo, uma nação sem ancestralidade ou ainda repor uma cultura inverídica deixa um legado de trauma e resistência" (SHOHAT; STAM, 2012, p. 42).

Quando o subalterno assume um lugar de silêncio, aqui consideramos a esteira teórica do questionamento de Spivak sobre a possibilidade de fala desse sujeito, as tradições não só enfraquecidas, mas há uma anulação total desse sujeito. Para Edward Said, o sujeito de identidade europeia (qualquer país europeu) e outro de identidade africana (qualquer país africano) estão marcados. Um ocupa lugar periférico e o outro lugar privilegiado e, em busca de deturpar essa lógica, é preciso fragilizar esses binarismos. Ou seja, Said precisou explicar sobre a identidade do oriente e esse ato ressignifica e desmonta a imagem inventada pelo ocidente. A unificação do continente africano na imagem se fosse um país vai além das razões óbvias de domínio, mas também, causa certo distanciamento e indiferença pelo o outro. Este outro, como disse Homi Bhabha (1992, p.186), no texto A questão do "outro": diferença, discriminação e o discurso do colonialismo local da cultura, anuncia "o poder colonial produz o colonizado como uma realidade fixa que é imediatamente em 'outro' e ainda inteiramente conhecível e visível”(BHABHA, 1992, p.186). Questionar as noções preconcebidas sobre uma nação ou povo estabelece o principal pensamento das correntes pós-coloniais, consolidando essa área como um campo teórico e influenciando os demais. Assim como a desconstrução derridiana abalou a compreensão sobre a filosofia da presença para o século XXI, a teoria póscolonial acende novas perspectivas de investigação nas demais disciplinas. As revisitações historiográficas precisavam de novos olhares para a antropologia, 


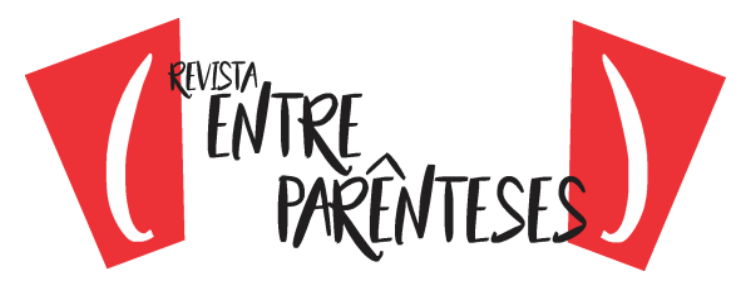

tornando também argumentos suscetíveis para uma nova postura das ciências políticas que pode ter dado origem aos Estudos Culturais.

Dessa forma, hoje, com a leitura de escritoras como Chimamanda Adichie, entre outras, acreditamos ser possível reconhecer os desdobramentos da exploração que não cessou mesmo depois do fim do período colonial. Neste artigo, questionamos sobre as responsabilidades do texto literário nesse processo de (re)interpretar os discursos sobre as imagens dos nigerianos.

\section{Kambili, a metáfora da própria Nigéria}

Para quem não pode acessar imediatamente 0 texto, aqui apresentaremos um breve resumo do enredo com foco nas personagens e no modo como relacionam-se entre elas e com o contexto em que estão inseridas. Purple Hibiscus está contextualizado em uma família lgbo que vive na parte sudeste da Nigéria no final do século XX. O enredo é narrado por Kambili, uma moça nigeriana que relata acontecimentos de dias vividos em sua adolescência. À época, a personagem, que nasceu em família economicamente abastarda, estava com quinze anos e era excessivamente introspectiva. Sua introspecção e insegurança a deixava tiravam-lhe os sorrisos e agia como se os pensamentos a torturassem. Havia constante embate entre o que pensava e o que ela se permitia expressar, colocar em palavras seus sentimentos. Parte dessa exigência por autocontrole era obrigação religiosa e censura paterna. Sua vida era rigorosamente controlada, estava acostumada à passividade (do latim passivus, ou seja, suscetível à paixão) e à subserviência. Dessa maneira, Kambili acreditava que a felicidade estava relacionada à obediência.

Nesse sentido, a personagem de Adichie é o resultado do processo de colonização, pois experimenta um mundo que é resultante de um processo de apropriações de uma nova cultura (do colonizador) e de uma antiga cultura (de seus ancestrais africanos). Os resquícios do passado que seu pai Eugene não consegue apagar perturba sua identidade frágil. Essa fragilidade se configura porque o pai de Eugene continua adorando os deuses africanos, e sua irmã mesmo sendo católica Revista (Entre Parênteses) 
aceita doutrinas e crenças pagãs, ou seja, tanto o pai quanto a irmã de Eugene são as fendas na sua sólida identidade. Desse modo, Eugene toma todas as atitudes possíveis para afastar a filha da presença desses personagens para que os filhos não sejam tentados pela dúvida:

Papa-Nnukwu had called an umunna meeting to complain to the extended family that he did not know his grandchildren and that we did not know him. Papa-Nnukwu had told Jaja and me this, as Papa did not tell us such things. Papa-Nnukwu had told the umunna how Papa had offered to build him a house, buy him a car, and hire him a driver, as long as he converted and threw away the chi in the thatch shrine in his yard. Papa-Nnukwu laughed and said he simply wanted to see his grandchildren when he could. He would not throw away his chi; he had already told Papa this many times. The members of our umunna sided with Papa, they always did, but they urged him to let us visit Papa-Nnukwu, to greet him, because every man who was old enough to be called grandfather deserved to be greeted by his grandchildren. Papa himself never greeted Papa-Nnukwu, never visited him, but he sent slim wads of naira through Kevin or through one of our umunna members, slimmer wads than he gave Kevin as a Christmas bonus ${ }^{3}$.(ADICHIE, 2003, fonte digital

Tal comportamento é ressaltado pela narradora quando compara o modo como o pai tratava seu outro avô. Kambili afirma o quão branco era o outro avô e o quanto ele era tido como um exemplo dentro de sua casa.

(...) It was so different from the way Papa had treated my maternal grandfather until he died five years ago. When we arrived at Abba every Christmas, Papa would stop by Grandfather's house at our ikwunne, Mother's maiden home, before we even drove to our own compound. Grandfather was very light-skinned, almost albino, and it was said to be one of the reasons the missionaries had liked him. He determinedly spoke English, always, in a heavy Igbo accent. He knew

\footnotetext{
3 "Papa-Nnukwu convocara uma reunião da umunna para reclamar com a família que ele não conhecia seus netos e que não o conhecíamos. Papa-Nnukwu havia contado isso para Jaja e eu, pois Papa não nos contou tais coisas. Papa-Nnukwu contara à umunna como o pai se oferecera para lhe construir uma casa, comprar-Ihe um carro e contratar um motorista, desde que ele se convertesse e jogasse fora o chi no santuário de palha de seu quintal. Papa-Nnukwu riu e disse que simplesmente queria ver seus netos quando pudesse. Ele não jogaria fora seu chi; ele já havia contado isso a Papa muitas vezes. Os membros da nossa umunna tomaram o partido do papai, sempre o fizeram, mas insistiram para que ele nos deixasse visitar o Papa-Nnukwu, para cumprimentá-lo, porque todo homem com idade suficiente para ser chamado de avô merecia ser saudado pelos netos. O próprio Papa nunca cumprimentou Papa-Nnukwu, nunca o visitou, mas ele enviou maços de naira através de Kevin ou através de umde nossos membros daumunna, maços mais finos do que ele deu a Kevin como um bônus de Natal" (nossa tradução).
}

Revista (Entre Parênteses) 
Latin, too, often quoted the articles of Vatican I, and spent most of his time at St. Paul's, where he had been the first catechist. He had insisted that we call him Grandfather, in English, rather than PapaNnukwu or Nna-Ochie. Papa still talked about him often, his eyes proud, as if Grandfather were his own father ${ }^{4}$. (ADICHIE, 2003, fonte digital)

Considerando o fanatismo religioso um dos eixos centrais da narrativa, o observamos como processo de "embranquecimento cultural" sofrido pela Nigéria durante o período de colonização. Como o romance se passa em um período pós o processo colonial consideramos Eugene a personificação dessa obediência e urgência pelo embranquecimento. Desse modo, o pai de Kambili não a deixa duvidar de que a desobediência resultaria em não ter direito aos céus. Para garantir a obediência da filha Eugene castigava Kambili com agressões psicológicas e agressões físicas:

\begin{abstract}
"Where is Chinwe Jideze?" Papa asked, when we got to the front of my class. A group of girls stood at the door, talking. I looked around, feeling a weight around my temples. What would Papa do? Chinwe's light-skinned face was at the center of the group, as usual. (...) "Look at her," Papa said. "How many heads does she have?"

"One." I did not need to look at her to know that, but I looked at her, anyway. Papa pulled a small mirror, the size of a powder compact, from his pocket. "Look in the mirror." I stared at him. "Look in the mirror." I took the mirror, peered at it. "How many heads do you have, gbo?" Papa asked, speaking Igbo for the first time. "One."

"The girl has one head, too, she does not have two. So why did you let her come first?"

"It will not happen again, Papa." A light dust lkuku was blowing, in brown spirals like uncoiling springs, and I could taste the sand that settled on my lips. "Why do you think I work so hard to give you and Jaja the best? You have to do something with all these privileges.
\end{abstract}

\footnotetext{
4 “(...) Era tão diferente da maneira como papai tratara meu avô materno até a morte dele, cinco anos antes. Quando chegávamos a Abba todo Natal, papai passava na casa do avô em nossa ikwunne, a casa de mamãe, antes mesmo de nos dirigirmos para nosso próprio complexo. $O$ avô era de pele muito clara, quase albino, e dizia-se ser uma das razões pelas quais os missionários gostavam dele. Ele falava com determinação inglês, sempre, com um forte sotaque igbo. Também conhecia o latim, muitas vezes citava os artigos do Vaticano I e passava a maior parte do tempo em St. Paul, onde fora o primeiro catequista. Ele insistira para que o chamássemos de avô, em inglês, em vez de papaiNnukwu ou Nna-Ochie. Papai ainda falava dele com frequência, os olhos orgulhosos, como se o avô fosse seu próprio pai" (nossa tradução).
}

Revista (Entre Parênteses) 


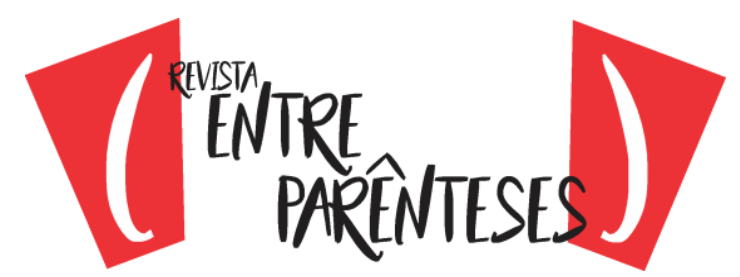

Because God has given you much, he expects much from you. He expects perfection ${ }^{5}$ (ADICHIE, 2003, fonte digital).

"Get up! Get away from that paiting!"

I lay there, did nothing.

"Get up!" Papa said again. I still did not move. He started to kick me. The metal buckles on his slippers stung like bites from giant mosquitoes. He talked nonstop, out of control, in a mix of Igbo and English, like soft meat and thorny bones. Godlessness. Heathen worship. Hellfire. The kicking increased in tempo, and I thought of Amaka's music, her culturally conscious music that sometimes started off with a calm saxophone and then whirled into lusty singing. I curled around myself tighter, around the pieces of the painting; they were soft, feathery. They still had the metallic smell of Amaka's paint palette. The stinging was raw now, even more like bites, because the metal landed on open skin on my side, my back, my legs. Kicking. Kicking. Kicking. Perhaps it was a belt now because the metal buckle seemed too heavy ${ }^{6}$.(ADICHIE, 2003, fonte digital)

Kambili estava acondicionada a uma postura constantemente inativa quanto à dominação cultural colonial, à intolerância religiosa e à violência familiar. $A$ narrativa pai-filha é alegoria da nação pós-colonial. Assim como no poema "Leda and the Swan", de William Butler Yeats, em que Leda é a metáfora da Irlanda

5 “'Onde está Chinwe Jideze?' Papai perguntou, quando chegamos à frente da minha aula. Um grupo de meninas estava na porta, conversando. Eu olhei ao redor, sentindo um peso ao redor das minhas têmporas. O que Papa faria? O rosto de pele clara de Chinwe estava no centro do grupo, como de costume. (...) 'Olhe para ela', disse Papa. 'Quantas cabeças ela tem?' 'Uma.' Eu não precisava olhar para ela para saber disso, mas eu olhei para ela, de qualquer maneira. Papa tirou do bolso um pequeno espelho do tamanho de um pó compacto. 'Olhe no espelho'.

Eu olhei para ele. 'Olhe no espelho'. Eu peguei o espelho, olhei para ele. 'Quantas cabeças você tem, gbo?' Papa perguntou, falando Igbo pela primeira vez. 'Uma'. 'A moça tem uma cabeça também, ela não tem duas. Então, por que você a deixou em primeiro lugar?' 'Isso não vai acontecer de novo, papai'. Um leve Ikuku estava soprando, em espirais marrons como molas desenroladas, e eu podia sentir o gosto da areia que se assentava em meus lábios.

'Por que você acha que eu trabalho tanto para dar a você e a Jaja o melhor? Você tem que fazer algo com todos esses privilégios. Porque Deus Ihe deu muito, ele espera muito de você. Ele espera perfeição'(...)" (nossa tradução).

6 '“Levante-se! Afaste-se disso!' Eu deitei lá, não fiz nada. 'Levante-se!' Papa disse novamente. Eu ainda não me mexi. Ele começou a me chutar. As fivelas de metal em seus chinelos picaram como mordidas de mosquitos gigantes. Ele falava sem parar, fora de controle, em uma mistura de igbo e inglês, como carne macia e ossos espinhosos. Godlessness. Adoração pagã. Fogo do inferno. $O$ chute aumentou em ritmo, e eu pensei na música de Amaka, sua música culturalmente consciente que às vezes começava com um saxofone calmo e depois se transformava em um canto vigoroso. Enrolei-me mais ao redor das peças da pintura; eles eram macios, emplumados. Eles ainda tinham o cheiro metálico da paleta de pintura de Amaka. O ardor estava cru agora, mais parecido com mordidas, porque o metal pousou na pele aberta do meu lado, minhas costas, minhas pernas. Chutando. Chutando. Chutando. Talvez fosse um cinto agora porque a fivela de metal parecia muito pesada".

Revista (Entre Parênteses) 
invadida pelos Ingleses, Kambili é a metáfora para a Nigéria colonizada e dividida. Quando jovem, a personagem representa o ser colonizado a quem, observando os postulados de Frantz Fanon, não é permitido o direito de se autoconhecer como ser humano individual e dentro de uma humanidade coletiva. Em certo momento, a protagonista chega a refletir sobre a sua incapacidade de rir:

(...)"How do they do that, Papa-Nnukwu? How do people get inside that one?" Jaja asked. (...) Aunty Ifeoma laughed and spoke in English. "Jaja, you're not supposed to say there are people in there. Didn't you know that?" (...) That night, I dreamed that I was laughing, but it did not sound like my laughter, although I was not sure what my laughter sounded like. It was cackling and throaty and enthusiastic, like Aunty Ifeoma's ${ }^{7}$. (ADICHIE, 2003, fonte digital)

As conjecturas de Fanon sobre sociedade provem do conceito marxista de alienação. Para Marx, a alienação seria a obstrução seriada de Gattungswesen, o "ser-espécie", que é organizada e produzida por um semelhante com a finalidade de produzir condições materiais e sociais específicas de existência. Condições essas que privilegiariam economicamente o grupo impostor, condição inerente, segundo o sociólogo, ao Capitalismo. Enquanto Marx se referia ao diálogo entre as classes sociais, Fanon procura ampliar o conceito para compreender o diálogo que se estabelece no processo de colonização. A condição colonialista delimitou um imaginário determinista pautado por questões étnicas como uma condição de hierarquia natural, quando era, na realidade, uma expressão de alienação econômica e social do colonizado. Para além dessas questões políticas, o colonialismo é responsável para cisão dos indivíduos colonizados de sua individualidade e cultura. Em Purple Hibiscus, a narradora nos informa que, o pai

(...) hardly spoke Igbo, and although Jaja and I spoke it with Mama at home, he did not like us to speak it in public. We had to sound civilized in public, he told us; we had to speak English. Papa's sister, Aunty Ifeoma, said once that Papa was too much of a colonial

\footnotetext{
7 “(...) 'Como eles fazem isso, Papa Nnukwu? Como as pessoas entram lá?', perguntou Jaja. (...) Tia Ifeoma riu e falou em inglês. 'Jaja, você não deveria dizer que há pessoas lá dentro. Você não sabia disso?' (...) Naquela noite, eu sonhei que estava rindo, mas não parecia o meu riso, embora eu não tivesse certeza de como minha risada soava. Foi uma gargalhada, rouca e entusiasmada, como a tia Ifeoma" (nossa tradução).
}

Revista (Entre Parênteses) 


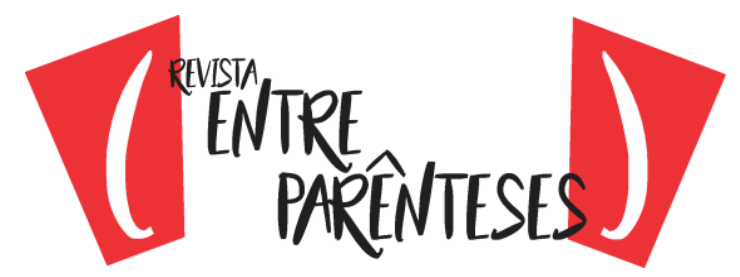

product. She had said this about Papa in a mild, forgiving way, as if it were not Papa's fault, as one would talk about a person who was shouting gibberish from a severe case of malaria ${ }^{8}$. (ADICHIE, 2003, fonte digital)

Para Fanon (1967), o indivíduo só é humano na medida em que tenta impor sua existência sobre outro indivíduo para ser reconhecido. Em contrapartida,

(...) as long as he has not been effectively recognized by the other, that other will remain the theme of his actions. It is on that other being, on recognition by that other being, that his own human worth and reality depend. It is that other being in whom the meaning of his life is condensed ${ }^{9}$ (FANON, 1967, p. 216)

A imposição de Eugene na vida de seus filhos e no modo como pensam é forte ao ponto de que Kambili, apesar de ser a narradora, tem seu discurso permeado pelas ideias do pai. Ao contrário da filha, o leitor percebe logo de início, na figura de Papa a evidência do mimetismo encorajado pelo discurso colonial, "o assujeitamento esquizofrênico ao imaginário europeu" (MIRANDA, 1994, p. 32). Como afirma Daria Tunca(2009), Eugene é um ser de personalidade multifacetada. Ao mesmo tempo em que é católico convicto e faz generosas doações para a igreja local, não faz uso dessa benevolência para com seu pai, que permaneceu fiel à religião tradicional Igbo. Ainda, ao mesmo tempo em que depõe contra a ditadura militar nigeriana no jornal que publica, em repetidas vezes ao longo da narrativa espanca sua esposa e seus filhos:

"What did you do there? Did you eat food sacrificed to idols? Did you desecrate your Christian tongue?" I sat frozen; I did not know that tongues could be Christian, too. "No," Jaja said. Papa was walking toward Jaja. He spoke entirely in igbo now. I thought he would pull at

\footnotetext{
8 "(...) dificilmente falava Igbo, e embora Jaja e eu falássemos com mamãe em casa, ele não gostava que falássemos em público. Nós tínhamos que parecer civilizados em público, ele nos disse; nós tínhamos que falar inglês. A irmã de Papa, tia Ifeoma, disse uma vez que Papa era um produto colonial demais. Ela havia dito isso sobre Papa de uma maneira gentil e generosa, como se não fosse culpa do Papa, como se fala sobre uma pessoa que gritava coisas sem sentido devido a um caso grave de malária" (nossa tradução).

9 “(...)enquanto não tenha sido efetivamente reconhecido pelo outro, esse outro permanecerá como o tema de suas ações. É sobre esse outro ser, no reconhecimento por esse outro ser, de que seu próprio valor humano e realidade dependem. É esse outro ser em quem o significado de sua vida é condensado" (nossa tradução).
}

Revista (Entre Parênteses) 


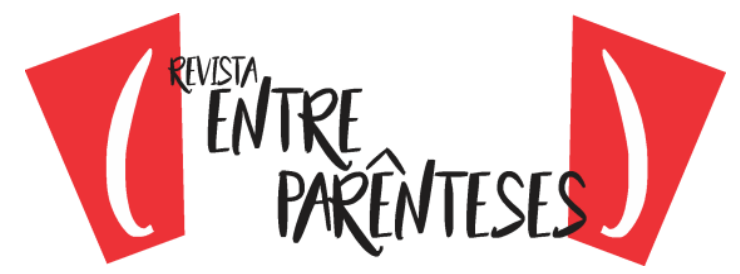

Jaja's ears, that he would tug and yank at the same pace as he spoke, (...) But he said, "I want you to finish that food and go to your rooms and pray for forgiveness" ${ }^{\prime 10}$. (ADICHIE, 2003, fonte digital)

Trata-se de alguém que assumiu para si e para sua família hábitos culturais, imagens, propósitos e princípios que vieram de fora de sua cultura natal. Assim, ele é uma cópia incongruente e que eiva a cultura local além de ser, mesmo sem perceber, ferramenta para a manutenção do poder ideológico do colonizador sobre suas colônias (BHABHA, 1985, p.35).

Adiche faz uma escolha significativa ao descrever os elementos da casa de Kambili como primordialmente claros, induzindo o leitor a compreender a tentativa de Eugene de se ambientar e agir o mais próximo possível dos brancos. Lembramos da descrição do quarto do personagem: "When I had thought of heaven as a child, I visualized Papa's room, the softness, the creaminess, the endlessness." Contudo, por mais que tente, ele não é Inglês e, portanto, sua túnica é descrita como "a long gray robe like the rest of the oblates, help redistribute as hevery year"11. Assim, ele é um ser cinza, um híbrido entre culturas: "to be Anglicized is emphatically, not to be English" (BHABHA, 2010, p. 128). O colonizador, o outro, também é marcado pela ótica da narradora:

Even though Father Benedict had been at St. Agnes for seven years, people still referred to him as "our new priest." Perhaps they would not have if he had not been white. He still looked new. The colors of his face, the colors of condensed milk and a cut-open soursop, had not tanned at all in the fierce heat of seven Nigerian harmattans. And his British nose was still as pinched and as narrow as it always was, the same nose that had had me worried that he did not get enough air when he first came to Enugu. Father Benedict had changed things in the parish, such as insisting that the Credo and kyrie be recited only in Latin; Igbo was not acceptable. Also, hand clapping was to be kept

\footnotetext{
10 'O que você fez lá? Você comeu comida sacrificada a ídolos? Você profanou sua língua cristã?' Eu sentei congelada; Eu não sabia que as línguas poderiam ser cristãs também. 'Não', disse Jaja. Papa estava caminhando em direção a Jaja. Ele falava inteiramente em igbo agora. Eu pensei que ele iria puxar as orelhas de Jaja, que ele iria puxar e puxar no mesmo ritmo enquanto falava, (...) Mas ele disse: 'Eu quero que você termine essa comida, vá para seus quartos e ore por perdão' (nossa tradução).

11 "Quando eu pensava no céu quando criança, visualizava o quarto de papai, a suavidade, a cremosidade, a imensidão" e "Um longo manto cinzento como o resto dos oblatos ajudou a distribuir cinzas todos os anos" (nossa tradução).
}

Revista (Entre Parênteses) 


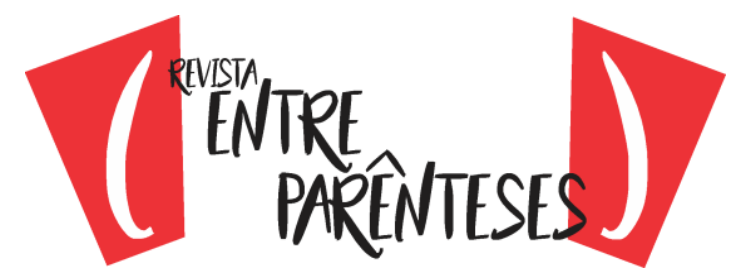

at a minimum, lest the solemnity of Mass be compromised. But he allowed offertory songs in lgbo; he called them native songs, and when he said "native" his straight-line lips turned down at the corners to form an inverted U12. (ADICHIE, 2003, fonte digital - grifos nossos)

Ao apresentar Padre Benedict, a partir de características físicas, a imagem de que ele não havia se adaptado ao ambiente, ao contrário, ficamos sabendo que ele realizou modificações para que o contexto melhor se adaptasse a ele. Dessa forma, há um contraponto entre ser new e ser white instaurado no imaginário coletivo dos fiéis e expresso pelo olhar Kambili. Uma vez que o romance se passa em uma época em que não se pressupõe a miscigenação entre as etnias, a marca de um British nose e de uma pele cor de condensed milk para caracterizar o personagem seriam, se não intencionais, de uso pleonástico. As descrições servem, portanto, para reforçar a figura do padre como a do "outro", daquele que não nos representa e que veio para nos impor suas regras. Padre Benedict, ao reformar os ritos e reduzir ao mínimo o bater de palmas, busca o apagamento de toda e qualquer partícula cultural que se encontre fora do discurso de pureza e unidade por ele pregados. O contexto exposto pela narradora marca, segundo Fanon, que "uma Igreja nas colônias é uma igreja de brancos, uma Igreja de estranhos. Ela não chama o homem colonizado para o caminho de Deus, mas para o caminho do branco, o caminho do senhor, o caminho do opressor" (FANON, 2010, p.59).

O contato de Kambilicom Papa-Nnukwue as tradições Igbo propiciado pela tia vão atuando como modificadores das opiniões da personagem. Inicialmente, ela considera manifestações mmuo segundo a opinião de seu pai. Quando passam de carro por um ritual, ela afirma:

\footnotetext{
12 "Embora o padre Benedict estivesse em St. Agnes há sete anos, as pessoas ainda se referiam a ele como "nosso novo padre". Talvez não o fizessem se ele não fosse branco. Ele ainda parecia novo. As cores de seu rosto, as cores do leite condensado e uma graviola aberta não tinham se bronzeado de todo no calor feroz de sete harmattanos nigerianos. E o nariz britânico ainda era tão apertado e estreito como sempre era, o mesmo nariz que me preocupara que ele não recebesse ar suficiente quando chegasse a Enugu. $O$ padre Benedict mudara as coisas na paróquia, insistindo que o credo e o kyrie fossem recitados apenas em latim; Igbo não era aceitável. Além disso, bater palmas deveria ser mantido no mínimo, para que a solenidade da Missa não fosse comprometida. Mas ele permitiu canções de oferendas em lgbo; ele os chamava de canções nativas, e quando ele disse "nativo", seus lábios retos se viraram nos cantos para formar um U invertido" (nossa tradução).
}

Revista (Entre Parênteses) 
Papa had driven us past the crowds at Ezilcheke once, some years ago, and he muttered about ignorant people participating in the ritual of pagan masquerades. He said that the stories about mmuo, that they were spirits who had climbed out of ant holes, that they could make chairs run and baskets hold water, were all devilish folklore. Devilish Folklore. It sounded dangerous the way Papa said it. (...) Amaka had already looked away. I looked away, too, toward the crowd of people that pressed around the car. ${ }^{13}$ (ADICHIE, 2003, fonte digital)

Mesmo curiosa, toma a manifestação e o fato de ter olhado como atos pecaminosos. Por ser condicionada a uma única verdade, é apenas a partir de seu contato com o jovem padre Amadi que ela passa a observar seu contexto de uma outra forma:

"I sleep in the same room as my grandfather. He is a heathen," I blurted out.

He turned to me briefly, and before he looked away, I wondered if the light in his eyes was amusement. "Why do you say that?"

"It is a sin."

"Why is it a sin?" I stared at him. I felt that he had missed a line in his script. "I don't know."

"Your father told you that." I looked away, out the window. I would not implicate Papa, since Father Amadi obviously disagreed. "Jaja told me a little about your father the other day, Kambili."I bit my lower lip. What had Jaja said to him? WhatwaswrongwithJaja, anyway? ${ }^{14}$ (ADICHIE, 2003, fonte digital)

Este contato traz uma ambiguidade de emoções e pensamentos. Em um momento da narrativa, quando eles voltam a casa da tia após mais uma cena violenta protagonizada pelo pai, ela não deseja atender sua ligação, mas, ao mesmo tempo, sente falta de reportar para ele sobre seu dia:

13 "Uma vez, Papa havia conduzido para longe da multidão em Ezilcheke, alguns anos atrás, e ele murmurou sobre pessoas ignorantes que participavam do ritual de máscaras pagãs. Ele disse histórias sobre mmuo, que eles eram espíritos que tinham saído de buracos de formigas, que eles podiam fazer cadeiras e cestas segurarem água, eram todos parte de um Folclore diabólico. Folclore diabólico. Soava perigoso do jeito que o Papa dizia. (...) Amaka já havia desviado o olhar. Eu também desviei o olhar para a multidão de pessoas que apertavam o carro" (nossa tradução).

14 "'Eu durmo no mesmo quarto que meu avô. Ele é um pagão', eu deixei escapar. Ele se virou para mim brevemente e, antes de desviar o olhar, imaginei se a luz em seus olhos era divertida. 'Por que você diz isso?' 'É um pecado'. 'Por que isso é pecado?' Eu olhei para ele. Eu senti que ele tinha perdido uma linha em seu roteiro. 'Eu não sei'. 'Seu pai Ihe disse isso'. Eu olhei para longe, para fora da janela. Eu não comprometeria Papa, já que padre Amadi obviamente discordava. 'Jaja me contou um pouco sobre seu pai outro dia, Kambili'. Eu mordi meu lábio inferior. O que Jaja disse a ele? $\mathrm{O}$ que havia de errado com Jaja?" (nossa tradução).

Revista (Entre Parênteses) 


\section{(...)"Has he called?"}

"Yes. Jaja refused to go to the phone, and I did not go, either."

"Did you want to?" He asked gently. It was not what I expected him to ask.

"Yes," I whispered, so Jaja wouldn't hear, although he was not even in the area. I did want to talk to Papa, to hear his voice, to tell him what I had eaten and what I had prayed about so that he would approve, so that he would smile so much his eyes would crinkle at the edges. And yet, I did not want to talk to him; I wanted to leave with Father Amadi, or with Aunty Ifeoma, and never come back ${ }^{15}$. (ADICHIE, 2003, fonte digital)

\section{Ao realizarmos a assertiva de que Kambili é a metáfora da Nigéria} compreendemos que ela representa uma face dos múltiplos processos identitários que refletem o contexto histórico do país durante ao longo da narrativa. Nesse sentido, a filosofa Anna-LeenaToivanen a define com "the national daughter", ou seja, a filha da nação. Há, contudo um determinismo nas palavras de Toivanen:

While Kambili has gained more self-assurance toward the end of the novel, it seems rather unlikely that she, as the national daughter in the allegorical sense, has the strength and determination needed to overcome the national crisis and to envisage a better future. The ending of the novel suggests that the surviving family has a lot of issues to negotiate. The future of the family-and, on a larger scale, that of the nation-depends largely on how the violent past is going to be worked through. However, the ending does not really promise a hopeful horizon, and it seems that Kambili remains passive and submissive in the face of familial and national tragedies and is far from becoming a genuine protagonist in the national narrative ${ }^{16}$.(TOIVANEN, 2013, p. 113)

\footnotetext{
15“(...) 'Ele ligou?' 'Sim. Jaja se recusou a ir ao telefone e eu também não fui'. 'Você queria?' Ele perguntou gentilmente. Não era o que eu esperava que ele perguntasse. 'Sim', eu sussurrei, então Jaja não ouviria, embora ele não estivesse nem na área. Eu queria falar com o papai, ouvir a voz dele, contar a ele o que eu tinha comido e o que eu tinha orado para que ele aprovar, para que ele sorria tanto que seus olhos se enrugariam nas bordas. E, no entanto, não queria falar com ele; Eu queria sair com o padre Amadi, ou com a tia Ifeoma, e nunca mais voltar" (nossa tradução).

16 "Embora Kambili tenha adquirido mais autoconfiança em relação ao final do romance, parece improvável que ela, como filha da nação no sentido alegórico, tenha a força e a determinação necessárias para superar a crise nacional e enfrentar um futuro melhor. $O$ final do romance sugere que o que sobrevive da família tem muitas questões a serem resolvidas. O futuro da família - e, em maior escala, o da nação - depende em grande parte de como o passado violento será trabalhado. No entanto, o final não promete realmente um horizonte de esperança, e parece que Kambili permanece passiva e submissa diante das tragédias familiares e nacionais e está longe de se tornar uma genuína protagonista dentro da narrativa nacional" (nossa tradução).
}

Revista (Entre Parênteses) 


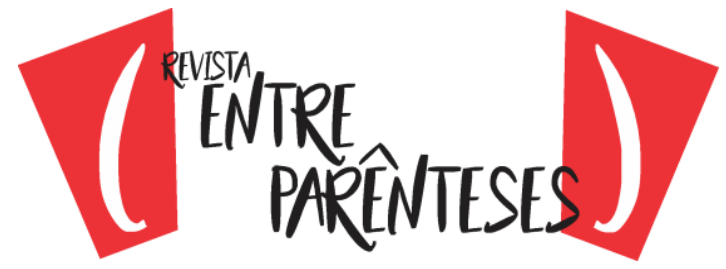

O final da narrativa, com o assassinato de Papa pela mãe, a prisão de Jaja e a partida da tia e de padre Amadi, não deixa ao leitor a sensação de que a família Achike cumpriu seu passado e está se preparando para um futuro melhor. Kambilipermanece ligada ao pai e as suas lembranças assim como a Nigéria permanece ligada ao seu colonizador.

\section{ALGUMAS CONSIDERAÇÕES}

Tunca (2009) lembra que as mudanças que Kambili sofre em sua personalidade ao longo do enredo foram notadas por muitos críticos. Se possível for dizer, Purple Hibiscus tem na mesma voz duas instâncias de discurso (BENVENISTE, 2005) contendo o eu: a narradora no presente e ela no passado. A nível narrativo, não sabemos se as marcas que analisamos aqui são provenientes do discurso da narradora enquanto vivenciava os acontecimentos ou da narradora enquanto contista de sua própria história. Contudo, a técnica salienta a violência do discurso colonial que se escreveu para dentro da Nigéria. A escrita de Adiche revela o contexto do país, as frustrações de um Estado-nação pós-colonial, a partir da relação pai-filha.

Ao contar seu passado, Kambili se posiciona como cidadã, "toma parte no fato de governar e ser governada" e se faz perceber dentro do contexto de "quem pode tomar parte no comum em função daquilo que faz, do tempo e do espaço em que essa atividade se exerce"(RANCIĖRE, 2009, p.16). Todavia, por mais que os leitores tenhamos acesso a sua voz, a personagem ainda não é capaz de se impor aos que a cercam, não inteiramente. Segundo Toivanen (2013), há uma certa inercia, um determinismo, e uma incerteza sobre o futuro. A figura paterna era apenas um dos exemplos de poderes que a colocam na posição de subalternidade, segundo propõe Spivak (1988). O contexto da narrativa é como um espelho dos reflexos da colonização na Nigéria.

O processo da colonização além de massificar o pensamento cultural sobre o continente africano também altera o pensamento de quem mora no lugar de exploração. As consequências da exploração colonial continuam interferindo nas Revista (Entre Parênteses) 


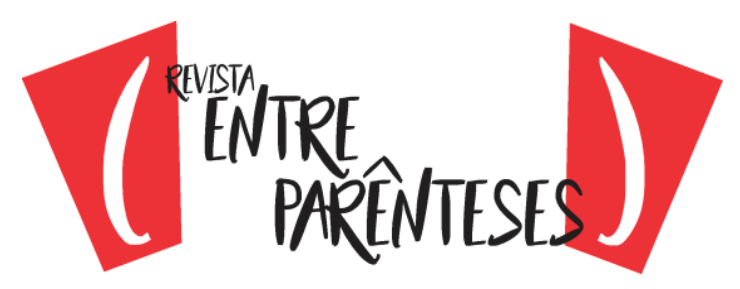

opiniões sobre os sujeitos explorados, desse modo, não se trata de exigir equidade cultural, mas é de desmanchar os parâmetros comparativos entre culturas e sujeitos, pois a imagem do colonizado precisa não ser colocado como o estático explorado. Nesse sentido, a literatura de Chimamanda consegue explorar figuras importantes do processo de reversão da estabilização do colonizado. É a complexidade dos personagens em conjunto com as instabilidades das instituições meios fortalecedores do texto: a aceitação da religião católica e o cotidiano de um país extremamente duplo - tradição e evolução - e inconformado com as repressões internas e externas.

\section{REFERÊNCIAS}

ADICHIE, Chimamanda Ngozi. Purple Hibiscus. London: 4th Estate, 2003.

The danger of a single story. TED Global, 2009. Disponível em <www.ted.com/talks/chimamanda_adichie_the_danger_of_a_single_story/transcript> Acesso em: 13 de abril de 2018.

BENVENISTE, Emile. Problemas de Linguística Geral. São Paulo: Pontes, 2005.

BHABHA, Homi K. The Location of Culture. New York: Routledge, 2010.

Signs takens from wonders: questions of ambivalence and authority under a tree outside Delhi. Critical Inquiry. Chicago, University of Chicago Press, 1985.

. A questão do "outro": diferença, discriminação e o discurso do colonialismo. In: HOLLANDA, Heloisa Buarque de (Org.). Pós-modernismo e política. Rio de Janeiro: Rocco, 1992.

Of Mimicry and Man: The Ambivalence of Colonial Discourse. Discipleship: A Special Issue on Psychoanalysis, vol. 28, p.125-133. Cambridge: The MIT Press, 1984.

FANON, Frantz. Black skin, white masks. New York: Grove Press, 1967.

Os condenados da terra. Juiz de Fora: UFJF, 2010. 


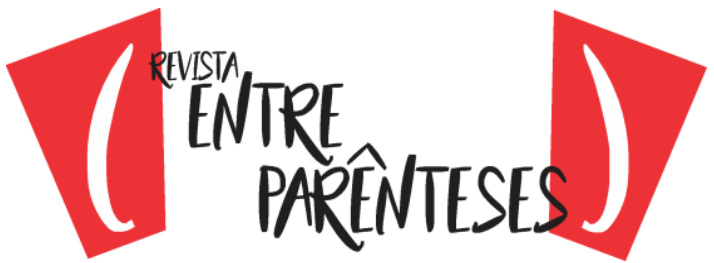

MIRANDA, Wander Melo. Projeções de um Debate. Revista brasileira de literatura comparada. Rio de Janeiro: Abralic, 1991.

RANCIÈRE, Jacques. A partilha do sensível. São Paulo: Editora 34, 2009.

SAID, Edward. Orientalismo: o Oriente como invenção do Ocidente. São Paulo: Companhia de Bolso,2007.

SHOHAT, Ella; STAM, Robert. Crítica da imagem eurocêntrica: multiculturalismo e representação (trad. Mário Soares). São Paulo: Cosac e Naify, 2006.

SPIVAK, Gayatri Chakrabarty. Can the subaltern speak? In: NELCON, C.; GROSSBERG, L. (org.) Marxism and the interpretations of culture. Basingstoke: University of Illinois Press, 1988.

TOIVANEN, Anna-Leena. Daddy's Girls?: Father-Daughter Relations and the Failures of the Postcolonial Nation-State in Chimamanda Ngozi Adichie's Purple Hibiscus and Véronique Tadjo's Loin de mon père. Ariel: a review of international English literature. Baltimore: The Johns Hopkins University Press and the University of Calgary, vol. 44, n. 1, p. 99-126, 2013.

TUNCA, Daria. Ideology in Chimamanda Ngozi Adichie's Purple Hibiscus (2003). English Text construction, Amsterdam, 2.1, p. 121-131, 2009. 